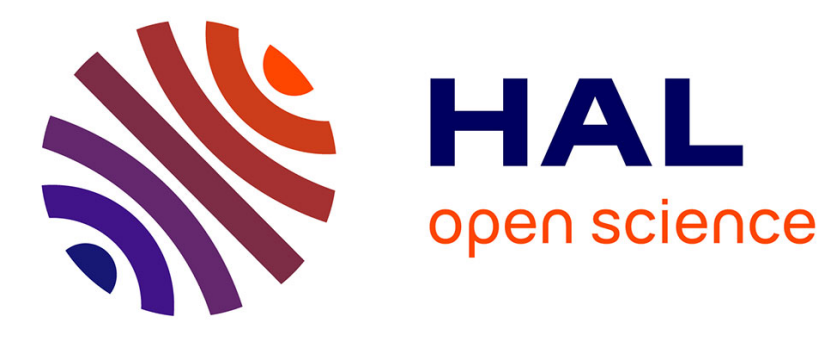

\title{
Scientific Processes in PISA Tests Observed for Science Teachers
}

\author{
Roser Pinto, Samira El Boudamoussi
}

\section{To cite this version:}

Roser Pinto, Samira El Boudamoussi. Scientific Processes in PISA Tests Observed for Science Teachers. International Journal of Science Education, 2009, 31 (16), pp.2137-2159. 10.1080/09500690802559074 . hal-00529574

\section{HAL Id: hal-00529574 \\ https://hal.science/hal-00529574}

Submitted on 26 Oct 2010

HAL is a multi-disciplinary open access archive for the deposit and dissemination of scientific research documents, whether they are published or not. The documents may come from teaching and research institutions in France or abroad, or from public or private research centers.
L'archive ouverte pluridisciplinaire HAL, est destinée au dépôt et à la diffusion de documents scientifiques de niveau recherche, publiés ou non, émanant des établissements d'enseignement et de recherche français ou étrangers, des laboratoires publics ou privés. 


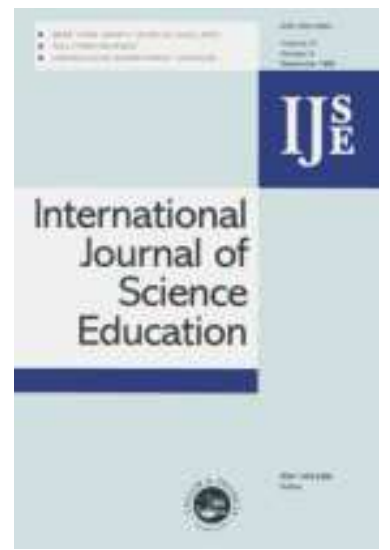

\section{Scientific Processes in PISA Tests Observed for Science Teachers}

\begin{tabular}{|r|l|}
\hline Journal: & International Journal of Science Education \\
\hline Manuscript ID: & TSED-2008-0341 \\
\hline Manuscript Type: & Research Paper \\
\hline Keywords: & teacher beliefs \\
\hline Keywords (user): & PISA, scientific processes, scientific competences \\
\hline \multicolumn{2}{|l}{} \\
\hline
\end{tabular}

\section{s ScholaroNE" \\ Manuscript Central}




\title{
Scientific processes in PISA tests
}

Scientific Processes in PISA Tests Observed for Science Teachers

\begin{abstract}
A research study, mainly based on the notion of 'scientific literacy' from PISA 2003 assessment framework, was carried out obtaining data from the administration of an open written questionnaire with items covering three central scientific processes: describing, explaining and predicting scientific phenomena, understanding scientific investigation and interpreting scientific evidence and conclusions, to 30 experienced in-service secondary school science teachers. The purpose was to analyse their views regarding the competences on the mentioned scientific processes assessed by Science PISA tests: which of the competences assessed were the most frequently identified by teachers, which of the competences they considered presenting difficulties for their students and, finally, which activities they used in their classes to promote similar competences. Our results indicated that teachers had different perceptions of one or other scientific processes considered relevant for scientific literacy in PISA framework. Their awareness of the expected students' difficulties did not necessarily match the competences intended to be assessed by neither PISA nor what they thought to be assessed. Moreover, their views differed depending not only on the type of scientific process but also on the underlying subject. Concern about the students' need of reading fluently with understanding and of paying special attention during the test time was also observed.
\end{abstract}

Keywords: PISA, Teachers' perceptions, scientific processes, scientific competences. 


\section{Introduction}

Since the OECD Programme for International Student Assessment (PISA) was launched in 2000, its media and social impact have been gradually increasing. From the first warnings about the relevance of such studies (Fenshan \& Harlen, 1999) to the claims for informing practice and educational policy everywhere (Baker \& Jones, 2005), great strides have been made. As a consequence of the publication of the first PISA results, in many countries important measures were approved at national levels to improve the countries' rankings in PISA (Moens, 2006). These measures have had significant implications and contributions to the questioning of recent reforms or the acceleration and implementation of the new and the ongoing ones (Ertl, 2006; Moens, 2006).

The impact and controversial characteristics of the PISA results, combined with the particularity of making the data available for researchers, have encouraged many of them to carry out research studies based on these data. At present, thousands of studies have elaborated evidence of the social relevance attached to such data and results. Most of these studies have used PISA data sets for further analyses of the reasons/factors behind the differences in results between countries (e.g., Lietz, 2006; Marks, 2006; Suchaut, Duru-Bellat, \& Mons, 2005; Turmo, 2004), for secondary analyses (e.g., Lie \& Linnakyla, 2004; Marks, 2006) or for re-interpretations of results (Ginsburg, Cooke, Leinwand, \& Pollock, 2005). Cross-national comparisons (e.g., Ginsburg, Cooke, Leinwand, \& Pollock, 2005; Kjaernsli \& Lie, 2004; van Langen, Bosker, \& Dekkers, 2006) as well as national comparisons between different provinces or regions within the same country have also been carried out (e.g. Willms, $2005 ; 2006)$. Other studies are more critical and question the real potential of international 


\section{Scientific processes in PISA tests}

comparative surveys based on school performance indicators (e.g., Simola, 2005) or discuss the problems related to the use of large-scale surveys (e.g., Goldstein, 2004; Wu, 2005).

From a pedagogical point of view, some studies are interested in the difficulty of items, measured by the percentage of students who correctly answered a given item and relate this to the content of the item (Ginsburg, Cooke, Leinwand, \& Pollock, 2005), to the difficulties of the translation of the item to different languages, to the familiarity of students with the content or context, to the test format (multiple choice items or constructed response items), or to the dependency of different items on the same context (Grisay \& Monseur, 2007). Only a few studies seem to be interested in the content of PISA items (e.g., Neubrand, 2004) or in the textual materials employed (Hatzinikita, Dimopoulos, \& Christidou, 2008) to assess students' scientific literacy rather than in the data sets. There are also studies interested in teachers' perceptions of external evaluations, such as PISA, as judgmental and controlling, which is contrasting with the view of internal school-based evaluation as a developmental process contributing to improve teachers' and students' learning (Livingston \& McCall, 2005). However, we did not find research studies about teachers' perceptions of the students' requirements that PISA tests suppose (El Boudamoussi, Tortosa, \& Pintó, 2008). It has been already well established that external evaluations have an important impact on the school, particularly in the selection of the content to be taught and the emphasis conferred to them. Therefore, if teachers understand the aims of the PISA items and if they are able to identify the competences assessed by those items, we assume, they will more likely promote such competences in their classes. Moreover, they will easily be aware of the difficulties of their students in relation to such competences. On the contrary, if they do not identify what the PISA tests are assessing, probably they will scarcely promote the competences assessed by PISA. We realise that teachers are grateful when they learn about the rationale of the PISA tests and when they understand the reasons for the low results of their students and what they 
could do to improve student learning. In our schools, the emphasis on learning the conceptual content is very high whereas the content about procedures, even though being part of the Spanish curriculum since the 1980s, has rarely been assessed; and therefore, these aspects of the official curriculum have scarcely had any repercussion in the real classes. It is expected that from such wide dissemination of the PISA results, no matter how many people disagree with them, more attention will be paid in our schools to make predictions, draw conclusions, infer from observations and so forth in a definitive direction to enhance students' scientific competences. To sum up, it is expected that schools will reap the benefits of the relevance given to such external evaluations in order to persuade teachers to promote the learning of a wide range of content in the curriculum.

\section{The PISA assessment framework}

The OECD Program for International Student Assessment (PISA) adopts a framework focused on the outcomes that are considered as required for all citizens (OECD, 2003). In this framework, 'literacy' is a key concept which is used for the three domains assessed by PISA: reading, mathematics, and science.

In our article and for our research purpose, we focus on the definition of 'scientific literacy' adopted by PISA $2003\left(\right.$ OECD, 2003) ${ }^{1}$. In this framework, scientific literacy is understood as:
'the capacity to use scientific knowledge, to identify questions and to draw evidence-based conclusions in order to understand and help make decisions about the natural world and the changes made to it through human activity' (p. 133).

PISA items are designed taking into account that the necessary capacities or competences for scientific literacy have always a base in scientific knowledge that students should be able to

\footnotetext{
${ }^{1}$ The PISA 2000, 2003 and 2006 frameworks present some nuances as to the definition of "scientific literacy" as well as to the organisation of the assessed domain of science. They are not relevant for our purpose in this paper.
} 


\section{Our research study}

Within the described framework, we are interested in knowing how well teachers are aware of the abilities or competences that students are required for doing a PISA test and to what extent teachers consider the test to be fostering these abilities and competences in their classes. Thus, the research questions to address these two aspects in our research study are:

1. Which are the competences assessed by PISA science items teachers most likely to identify?

2. Which are the difficulties teachers consider their students will experience when faced with the items?

\footnotetext{
${ }^{2}$ The framework for PISA 2006 differs in some extent to the presented above. Particularly, it refers to scientific competences as the scientific processes considered in PISA 2003, it takes into consideration the attitudes in science and regard the relevance in knowledge of science as well in knowledge about science
} 
3. Which activities are teachers proposing in their classes that they consider would promote any of the competences required to answer the PISA items?

\section{Methodology and Samples}

The selected PISA items

In order to analyse teachers' views regarding the competences assessed, a selection of eight science items from four units of the PISA 2003 and PISA 2000 (OECD, 2002) assessments was done. In Annex 1, there is the text of the items selected from the unit Stop that Germ and the text of the other three units are available online at http://antalya.uab.es/crecim/PISA_study :

2 items from the unit ;Stop that Germ! (the first two items in the PISA unit)

3 items from the unit Peter Cairney $\left(1^{\text {st }}, 2^{\text {nd }}\right.$ and $3^{\text {rd }}$ items of the unit)

1 item from the unit Corn $\left(3^{\text {rd }}\right.$ item of the unit)

2 items from the unit Ozone $\left(1^{\text {st }}\right.$ and $4^{\text {th }}$ items of the unit)

Each item in a unit is designed to assess at least one of the three scientific processes defined above. They cover all three processes defined by PISA, even though not all the aspects described in the definition of each process are considered.

We prioritized those items in which the context is more familiar to students and which entail concepts tackled in their science curriculum. We also intended not to include items or units which require long text reading. Table 2 shows the process for which each item is designed by PISA to assess and the particular aspect of that process from those defined in the list of descriptors of Table 1.

[Insert Table 2 about here] 


\section{Scientific processes in PISA tests}

\section{The sample}

The sample of teachers who took part in this study included 30 experienced in-service secondary school science teachers with different scientific backgrounds. Nineteen natural sciences teachers (biologists or earth scientists) and 11 physical sciences teachers (chemists or physicists) voluntarily accepted to participate in the study.

\section{Data collection}

In order to address the research questions we used a written questionnaire with openended questions, without pre-established lists of processes, difficulties or activities to select, in order not to influence teachers' responses. It was made up of three questions corresponding directly to the three research questions:

1) Which are the competences that you consider to be assessed by each of the items of this hypothetical test (elaborated with PISA items)?

2) Which are the difficulties that you think your students may have to respond to an evaluation test of this type?

3) Name briefly examples of activities that you usually use in your classes to promote some of the competences you have previously identified in the sample test.

For each item, each teacher's responses were categorised and, in case of more than one response from the same participant we assigned a single category in order to obtain a clearer picture of their view. In doing so, we chose the response or part of it, which corresponded most to the main scientific process assessed by PISA, and disregarded the other aspects. The descriptors in Table 1 guided the categorisation, even though in some cases they are not enough clear and made it difficult to codify teachers' responses.

The two authors carried out the categorisation independently, then compared their results and reached a consensus in the problematic cases. 


\section{Results and discussion}

The results of this study are organised into three main parts. The first part presents the results obtained from the analysis and categorisation of teachers' responses related to the first research question. In the second part, we focus on the teachers' perceptions of the expected difficulties that these items would have for their students (second question). The third part focuses on the activities described by the participants as examples of what they are carrying out in their classes in order to enhance similar competences as those assessed by PISA in each item (third question).

First question: Teachers' perceptions of the processes assessed by PISAs science items

Teachers' responses about the scientific processes they perceived are assessed by each item were categorised according to the three scientific processes considered by PISA 2003: describing, explaining and predicting scientific phenomena (Process 1); understanding scientific investigation (Process 2); and interpreting scientific evidence and conclusions (Process 3). In addition to these three categories, two more categories were needed: 'Using cognitive skills', which includes the responses that refer to students' competences such as the ability to think accurately, reason, be concentrated on the issue and so forth, and 'Other', for vague or non-specific responses.

\section{$\underline{\text { Results referring to the unit } i \text { Stop that Germ! }}$}

- Item 1 presents a doctor, Zabdiel Boylston, who scratched the skin of his six-year-old son and that of 285 other people and rubbed pus from smallpox scabs into the wounds in order to carry out an experiment to test an idea related to the immune system and the smallpox disease. It is intended to assess the competence of students for analysing scientific investigations (Process 2) and we found only five out of 30 (about 20\%) participants recognizing it with responses such as: 'Identify a scientific issue in a text (scientific methodology)'; 'Identify the hypothesis'. Most of the responses (about 60\%) 
In the case of Item 2, in the same context of the above item, students were asked for additional information that would be needed to decide how successful it was to test Boylston's idea with the approach given to his experiment. Almost $40 \%$ of the participants considered that the item was assessing Process 2: understanding scientific investigation. Teachers' responses coded as belonging to this Process 2 were, for example:

'Knowledge of "scientific methodology" and design of experiments to prove hypothesis, design other experimental procedures in order to generalise results'; 'Find the variables in an experiment and control them'. About $25 \%$ of the participants attributed it to Process 1 and about $10 \%$ gave responses regarding the question as assessing Process 3: interpreting scientific evidence and conclusions.

\section{$\underline{\text { Results referring to the unit Peter Cairney }}$}

Item 3 requires scientific knowledge about kinematics and asks students to select, from a list of four actions, the one that would help a supposed researcher, Peter Cairney, to be sure that his advice concerning the effect of painting lines on narrow roads was appropriate. Fifty percent of the participants provided responses which could be considered as closer to Process 2. Typical teachers' responses assigned to this category were: 'Ability to identify the issue or the key question in a scientific investigation'; 'Competence to select which evidence need to be obtained in a scientific investigation, in order to draw adequate conclusions and be able to make founded decisions'. About $25 \%$ of the participants referred to each of the other two processes (See Table 3).

[Insert Table 3 about here] 
Item 4 provides students with some results, obtained by Peter Cairney, about how the traffic has changed on one stretch of a narrow road after the lane lines were painted. On the basis of these results, it is supposed that the decision made was that lane lines should be painted on all narrow roads. Students are asked whether they think this was the best decision and to give reasons for agreeing or disagreeing. Therefore, this item focuses on the students' capacity to give reasons for or against a given conclusion in terms of the data provided and, thus it is designed to assess Process 3: interpreting scientific evidence and conclusions. Almost 60\% of the participants provided responses which could be categorised under this Process 3. In teachers' responses identifying such PISA intentions, we found sentences such as 'to draw conclusions from data'; 'Explain an opinion on the basis of data, analyse and interpret data' and so on. The way in which the question was asked as well as the involved curricular subject (kinematics), which is usually very familiar to science teachers in secondary school, might have influenced teachers' responses. This is contrary to the situation in Item 1.

About $10 \%$ of the participants referred to Process 1 as being assessed by this item and $10 \%$ referred to Process 2. A percentage of nearly $20 \%$ referred to competences that could be categorised as 'Reading comprehension' and 'Using cognitive skills'. Their responses included, for example, the ability to 'use arguments'.

Item 5 asks students to explain why a faster car takes more distance to stop than a slower one. The participants' responses referred to ideas that correspond to Process 1 in $90 \%$ of the cases (see Table 3). We find explanations such as: ‘Applying studied concepts’.

\section{$\underline{\text { Results referring to the unit Corn }}$}

Item 6 provides information about the relative greenhouse effect per molecule of gas of the four most important gases causing it: carbon dioxide (1), methane (30), nitrous oxide (160), and chlorofluorocarbons (17000). From this data, a researcher concludes that carbon dioxide 
is not the main cause of the greenhouse effect. Students are told that this conclusion is premature and that further information is needed and, this Item 6 asks them to choose among four types of data which are the most appropriate to be collected in order to conclude whether or not carbon dioxide is the main cause of the greenhouse effect. This item focuses on the students' competence to identify the assumptions made in reaching a conclusion (Process 3) Only about $10 \%$ of the participants seemed to be able to identify this Process 3 of interpreting scientific evidence and conclusions (see Table 3). Typical teachers' responses were: 'To be aware of the descriptions that are not supported by enough data' and 'Validity of opinions, how to infer correctly'. The largest number of participants, slightly more than $40 \%$, actually referred to aspects more related to Process 1 , followed by a $40 \%$ whose responses referred to Process 2 as being assessed by this item (See Table 3 ).

\section{Results referring to the unit Ozone}

Item 7 asks students to write, using the words atoms and molecules, an explanation of a comic strip where oxygen molecules are represented, and split and recombined into ozone molecules. We found the same $90 \%$ of teachers' responses identifying Process 1, for which Item 7 is in fact designed. They talked about applying or transferring concepts to real-life situations, using and recognizing models, giving explanations and so forth. For example, one of them said, 'Ability to explain phenomena from real life with concepts studied at high school'. The rest of participants gave responses that should be distributed among the other four categories as indicated in Table 3.

Finally, Item 8 asks students two questions about whether these questions can be answered by scientific research or not. Around $50 \%$ or 16 participants could identify Process 2 as being assessed by Item 8 . We found responses such as: 'Differentiate between a scientific 
investigation and any other kind of study or investigation'; 'distinguish between the questions that can be scientifically investigated and those that cannot'.

About $30 \%$ or nine participants provided responses that should be categorised under Process 1 and about $7 \%$ or two participants considered that the question asks students' possibility to use Process 3. Other responses referred to more general aspects, such as the ability to 'associate a scientific question with a problem to be investigated [...]'.

\section{Comparing the results to Question 1 for different items assessing the same scientific process}

As indicated by Table 3, the process of describing, explaining and predicting scientific phenomena was identified by most of the participants $(90 \%)$ when the items (5 and 7) required it.

In four of the items (1, 2, 3 and 8), teachers had to identify the process of understanding scientific investigation (Process 2); however, only 50\% or less of them did this (see Table 3). The participants seemed less likely (less than 40\%) to identify students' ability to recognise the additional information needed in a scientific investigation (Item 2). The percentage was higher (more than 50\%) when the competences assessed refer to recognising scientifically investigable questions (Item 8). The intermediate result of $50 \%$ was obtained when participants had to recognise the students' ability to identify the action to carry out in order to collect relevant data needed in a scientific investigation (Item 3).

The special case is Item 1 where Process 2 was identified as a matter of assessment for less than $20 \%$ of the participants. In fact, it can be a matter of discussion if Item 1 assesses the competence of understanding scientific investigation, as it is claimed by PISA specifications, instead of the competence in Process 1. This is because since students are asked: 'What idea might Zabdiel Boylston have been testing?' and, the expected right answers for the PISA team are: The idea that infecting someone with smallpox provides some immunity and the 
idea that by breaking the skin, smallpox is introduced into the blood stream. The argument of the PISA team is that in this item the main challenge is not the knowledge required; they consider that students 'should not demonstrate their understanding' even though they are required to use it to apply to a novel situation.

As we may notice from Table 3, there is a substantial difference between the number of teachers who correctly identified the process in the two items designed by PISA to assess the process of interpreting scientific evidence and conclusions. The percentage of participants was much higher when they had to identify student's ability to give reasons for or against a given conclusion in terms of the data provided (Item 4), than when this ability was to identify the assumptions made in reaching a conclusion (Item 6).

Table 3 also shows that interpreting scientific evidence and conclusions is a process scarcely identified by teachers.

We could conjecture that in the cases where participants were not skilled to identify the competences intended to be assessed (Items 1 and 6) and the required scientific knowledge is not trivial, they tended to assign what is being assessed to the process of describing, explaining and predicting scientific phenomena. Everything happens as if teachers consider that students should recall and use the scientific knowledge necessary to answer the question and not so much that other competences are required. This assertion could be clearer for Item 6 than Item 1, previously analysed. In Item 6, students should deal with chemical concepts and also should make an intellectual exercise of ruling out different options of data to be used to conclude whether or not carbon dioxide is the main cause of the greenhouse effect. So, Process 3 was not frequently identified and it was almost not recognised by any participant in this case where chemical ideas have to be brought into play. New analyses with other items and samples should be necessary to confirm this preliminary supposition. 
Second question: Teachers' perceptions of the expected difficulties of the PISA science items for students

The responses to the second question, aimed at analysing the teachers' perceptions, about which difficulties more likely students will find in answering the PISA tests, were also analysed and coded according to the three scientific processes considered by PISA within its assessment framework. During the analysis, we had to add two new categories in order to include difficulties considered relevant by the teachers and not directly related to any of the three scientific processes. In total, five categories were used; the additional ones were 'Reading comprehension' (in order to understand the contextualisation of a text or the paragraph), and 'Using cognitive skills'. Table 4 shows the results for the different eight items.

[Insert Table 4 here]

Results referring to the unit iStop that Germ!. Table 4 indicates that the expected difficulties mentioned by most teachers in the case of Item 1 ('What idea might Zabdiel Boylston have been testing?'), are related to Process 1 (about 70\%) even though this particular item was designed by PISA to assess Process 2 (see Table 2). The teachers seem to have in mind in the first place that students had a lack of scientific knowledge to answer the question especially because it deals with concepts not covered in the school curriculum ('At 15 years old, students have not seen [studied] the topic of immunology'). As well, five participants, nearly 20\%, mentioned 'Reading comprehension' as a main difficulty for their students to answer Item 1: 'Long text, they cannot follow the sequence of events'.

In the case of Item 2, ('Give two other pieces of information that you would need to decide how successful Boylston's approach was') also designed by PISA to assess Process 2, we found that nearly $40 \%$ of the participants referred to the competence in Process 1 as a difficulty for their students (see Table 4). One of them said, 'They [students] would not 
answer because they do not know the immune system'. Process 2 comes in the second place, with around $30 \%(26.7 \%)$ of the participants mentioning it as a difficulty for their students ('Not knowing the scientific methodology and how to design experiments') and another percentage of nearly $30 \%$ considering that students would have difficulties of 'Reading comprehension' ('not understanding what the question asks for') (See Table 4).

We can consider the whole unit ¡Stop the Germ! with its Items 1 and 2, and compare the competences identified by the teachers as a matter of assessment with the difficulties they would expect for their students, that is, teachers' responses to Questions 1 and 2 (see the figures in Tables 3 and 4).

Considering the whole unit, we realise that the difficulties that teachers would predict for the students were very much focused on the competence to describe, explain and predict scientific phenomena or on 'Reading comprehension'. However, as we have noted previously, the PISA team considered the two items are assessing the competences of students for Process 2: understanding scientific investigation.

As commented above, most of the teachers did not believe that their students would be able to deal comfortably with the scientific phenomenon of immunity and this seems to be a barrier for considering the experimental facet of the items, especially Item 2. The required scientific knowledge for correctly answering the question would operate as an obstacle, according to the teachers' views, for thinking how to design the scientific research of Mr Boylston. Moreover, many of them believed that students would not be able to read to understand the text. The difficulties mentioned by teachers go in diverse directions but rarely indicate that students will not be able to understand how to do a good piece of research, as it is supposed that the item measures.

Results referring to the Unit Peter Cairney: The largest number of participants, even though less than $40 \%(36.7 \%)$ of them referred to the process of understanding scientific 
investigation as an expected difficulty for answering Item 3 (see Table 4), which is in agreement with the purpose of the PISA item designers. Difficulty to 'Identify correctly the control variables that affect the results', 'They are not used to design experiments' and 'Not understanding that there are variables that affect the investigation (...)' were teachers' common responses. We realise that teachers also believed, in relatively large percentages, that students would have problems in 'Reading comprehension', as well as difficulties in reasoning or, in paying attention and so on ('Using cognitive skills').

In the case of Item 4, designed to assess the competence in interpreting evidence and draw conclusions, the teachers' perceptions were very heterogeneous. There was not an accumulation of responses assignable to Process 3, as could be expected but all the categories received similar number of responses. Responses such as 'They [students] are not able to extract conclusions from an experimental observation and they are not used to justifying their decisions (...)' were almost as frequent as others such as '... difficulties in identifying the problem and the variables that define it'; 'Relate the results with the experimental design' 'Lack of common sense', 'difficulties with reasoning' and so forth.

The difficulties that teachers assigned to Item 5, are mainly related to Process 1 followed by 'Reading comprehension' difficulties, about 13\% (see Table 4). The responses that we considered within the first category referred to students' failure due to the lack of the scientific knowledge required and the difficult concepts involved ('Not knowing the fact that should be explained'; 'Not knowing the laws of kinematics and dynamics'), as well as to the lack of the scientific terminology required to give an explanation ('They [students] would not use the appropriate scientific terminology'). Many references to the use of appropriate vocabulary or to the fluency of reading were also found. To be able to explain why a car takes more time to stop when its velocity is higher, should not be difficult for students since 
Kinematics has been a school subject for all the 15-year-old students. Then, the slightly less than $75 \%$ of the responses in the first category does not seem exceptional (see Table 4).

According to the PISA team, the three items of Peter Cairney Unit are assessing different competences of students (Process 2 for Item 3, Process 3 for Item 4 and Process 1 for Item 5) and for the three items, the source of the difficulties assigned to a particular item matches in a higher percentage with the kind of process that the item is intended to assess. Even so, the percentages vary greatly from about $27 \%$ to $73 \%$ (see Table 4 ).

We can consider the whole unit Peter Cairney, with its Items 3, 4 and 5, and compare the competences identified by the teachers as a matter of assessment with the difficulties they would expect for their students, that is, teachers' responses to Questions 1 and 2 of the questionnaire (see the figures in Tables 3 and 4).

We are not in the same situation here than Items 1 and 2 of $i$ Stop that Germ! Unit since the Peter Cairney Unit refers to Kinematics, a common school subject for all the 15-year-old students. We realise that, when an item, such as Item 5, is designed to assess Process 1 , it is more likely that teachers identified this process in the question formulated to students and also they considered that mastering such competence in describing, explaining and predicting scientifically was the main difficulty that students would have to overcome when answering the item. If the item, such as Item 3, is designed to assess the competence of students on Process 2, less than half of the teachers in the sample were able to identify it but the kind of difficulties expected by the teachers were mainly for Process 2 . Also difficulties related to the right use of cognitive skills and to the fluency in reading for comprehension were predicted in many cases. When students have to draw conclusions from evidence, as it appears in Item 4, 17 or more than half of the participants were aware of this intention of the item but there was little homogeneity in their expected possible causes of students' difficulties; they gave different kind of reasons: cognitive capabilities of students, fluency in understanding the text, 
mastery of scientific knowledge to be applied or, understanding scientific investigations. The largest gap between what teachers identified as a matter of assessment and what teachers perceived as difficult for their students to answer well was found for Process 3 in this Unit.

Results referring to the unit Corn (and particularly Item 6 where students should decide what data are necessary to collect in order to get a logical conclusion about the gases causing the greenhouse effect): Most of the difficulties mentioned by the participants correspond to Process 1; even though the item is designed for assessing the students' competence on Process 3. Common opinions were: 'lack of updated information about the causes of the greenhouse effect in order to compare data'; 'Difficulties with some concepts: greenhouse effect, molecule, photosynthesis...'. The context of Item 6 is long and it makes use of many scientific concepts before it arrives at formulating any question. It seems as if instead of concentrating on "which other data Karin need(s) to collect in order to conclude whether or not carbon dioxide is the main cause of greenhouse effect', the participants perceived that a large number of prior concepts were needed for selecting the appropriate source of data.

Many other teachers believed that students would have problems in understanding the text that, in fact, we find very long and rather confusing (see Table 4). For example, one teacher said, 'Besides the reading comprehension I do not see many difficulties'.

The rest of the participants either referred to Process 2 (about 7\%): ('Understand the different variables that intervene and their relative importance in the greenhouse effect') or to 'Using cognitive skills' (about 7\%): ('I think that they [the students] will answer intuitively but few of them will read the whole text again') (see Table 4).

Comparing the results from the first and second question (see Tables 3 and 4), we observe a special problem in Item 6. As shown previously, teachers rarely identified this item as assessing the students' competence of interpreting evidence and drawing conclusions. This is 
probably the cause that no one mentioned any difficulty related to the competence in Process 3 and attributed most of the difficulties mainly to the lack of knowledge in chemistry and their poor competence in reading comprehension.

Results referring to the unit Ozone: Most of the participants (about 67\%) referred to the ability on describing, explaining and predicting scientific phenomena as the expected difficulty for answering Item 7, in accordance with the purpose of the designers (see Table 4). Teachers considered that students would have problems in explaining the strip about the Ozone formation, due to the lack of the scientific knowledge required and the concepts involved, as well as the lack of the scientific terminology required to give an explanation ('To confuse the different levels of matter structure and composition'; 'the concepts of atom and molecule may not be clear for them'; ‘[... ability to use the correct vocabulary'). Again, a relatively high percentage (30\%) referred to 'Reading comprehension' ('too much reading for their age') as a main difficulty that students would have for correctly answering the question.

Finally, in the case of Item 8, the largest number of participants (about 40\%) mentioned the process of understanding scientific investigation as the expected difficulty that students could have (see Table 4). 'They [students] do not know what 'scientific investigation' means', 'Difficulty to distinguish between questions that can be solved by investigation and others that have a political character (...)' or Not understanding the question since they do not know how the CFC acts and how long it takes to act once it is released' were typical responses from the teachers.

Considering the results of the whole unit Ozone (see Tables 3 and 4), we realise that the process identified as a matter of assessment was also contemplated by teachers as the main source of difficulties for students in both Items 7 and 8 . We observe, thus, the coherence between the focus of the items and the centre of expected difficulties. Again, we also observe the high sensitivity of teachers in being aware of other difficulties students could have due to 
the required ability in reading with understanding and the demand of good thinking, reasoning, being concentrated and so forth.

Comparing the results to Question 2 for different items assessing the same scientific process

The results seem to indicate that the participants were more aware of the competences related to Process 1 as representing difficulties for their students, not only when it is the main process that is assessed (Items 5 and 7), but also when other processes are assessed (Items 1, 2 and 6). This makes the difficulties related to Process 1: describing, explaining and predicting scientific phenomena_as the most frequently mentioned process by participants in the case of five items out of eight (see Table 4).

The maximum proportion of participants who referred to Process 2 as an expected difficulty was $13 / 30$ (about $43 \%$ ) compared to $22 / 30$ (about $73 \%$ ) who referred to Process 1. In addition, when the participants considered Process 2 (assessed by the Items 2, 3 and 8) as the main difficulty, the highest percentage was always less than half (43.3\%) of the total (see Table 4). That is, the most probable items to be considered difficult for students are those designed to assess Process 1

The process of interpreting scientific evidence and conclusions was the least frequent difficulty mentioned by the participants (see Table 4). The percentage of the teachers that considered this Process 3 as the main difficulty for their students was lower than $30 \%$ in the case of Item 4 and nil in the case of Item 6, both designed to assess this process.

It is important to note that the teachers also referred to 'Reading comprehension' as a difficulty for their students in answering almost all the selected PISA items. The proportions of these teachers ranged from $13 \%$ to $30 \%$ of the participants. The same can be said for the difficulties of 'Using some cognitive skills' required for answering the test. 
The fact that the participants were more likely to perceive Process 1 as a difficulty for their students than Processes 2 and 3 may lead us to think that teachers considered that these two last processes did not represent properly students' difficulties. But, it may also be interpreted differently. As these two processes were not mainly on the teachers' minds, it is not probable that they were sensitive to them when considering students' difficulties in learning.

\section{Cross-analysis}

In order to examine whether the difficulties identified by the participants correspond to the process that they believed to be assessed by each item, we cross-analysed their responses to the first and second questions of our questionnaire, that is about the competences identified and about the difficulties foreseen.

Table 5 represents the total numbers of the teachers' responses assigned to any of the four categories considered (corresponding to the three scientific processes assessed by PISA and the other combined category: reading comprehension and using cognitive skills) as assessed competences and as expected students' difficulties.

\section{[Insert Table 5 here]}

Table 5 indicates that when a participant considered Process 1 as being assessed by a PISA item, probably he/she also referred to it as a possible difficulty for their students. This happened in 73 responses out of 113. However, when the participants identified Processes 2 or 3 as assessed competences, they tended to mention other competences as difficulties for their students in a total of 40 responses out of 65 and in 32 responses out of 39, respectively. Among the 39 out of 240 responses (16\%), in which the participants identified Process 3: interpreting scientific evidence and conclusions as being assessed by an item (from Items 1 to 8), only seven responses referred to this process as a difficulty for the students. Similar 
situation can be said for Process 2, in which only 25 responses, out 65 , referred to this process (see Table 5).

In other words, in the cases of Processes 2 and 3, the difficulties teachers expected for their students are generally not related to the competences they considered to be assessed by the item or required for them to answer it correctly. This could be attributed to their lack of the knowledge of the shortcomings of their students but, taking into consideration the wide professional experience of the participants, such interpretation would not be plausible. Teachers with long experience are usually knowledgeable of the students' limitations. Instead, perhaps a confused identification of the competences required by each item would be a more plausible interpretation of these results. Thus, we can confirm much consistency when discussing the results about Process 1 but not about those in Processes 2 and 3. Moreover, we can also notice that, in 83 out of 240 responses, teachers considered that the difficulties they expected for their students would not come from the processes assessed but from other obstacles, such as the demand of high cognitive skills or high competence in reading comprehension. We can conjecture again if this difference may be due to teachers not being aware of the processes assessed or the relevance assigned to the skills in these processes.

Third question: Teachers' perceptions of the activities they usually carry out to enhance similar competences to those required by the PISA items

Finally, the questionnaire administered to the participants included a third question, about which competences, among those assessed by the selected PISA items, teachers consider that they usually promote in their classes. The participants' responses were thus analysed and categorised according to the three scientific processes and the categories 'Scientific communication' and 'Others'. A large number of activities (106) were described by the participants.

[Insert Table 6 here] 
The results summarised in Table 6 indicate that $37 \%$ of the activities described by participants are related to the process of describing, explaining and predicting scientific phenomena. These activities generally referred to transferring school knowledge to everyday life or explaining phenomena using ideas previously taught ('I ask them to search for (books, films, press...) news, texts so that they can talk about it'; 'Occasionally I ask them to explain what they have supposedly learnt, in other words').

The second category cited by the participants corresponds to Process 2 . About $25 \%$ of the total activities described by the participants could be considered in this category. Most of these activities referred to carrying out or designing experiments ('small experiments in the classroom with various variables to be controlled'; 'design of simple experiments in which students have to identify measurable variables').

A low proportion (13\%) of the activities described by the participants corresponded to the category of interpreting scientific evidence and conclusions. They include activities leading to the interpretation of results, the extraction or formulation of conclusions ('We put an emphasis on the steps to be followed when doing a good experiment to extract valid conclusions').

Sixteen participants described activities that could be considered in the category of 'Scientific communication', representing $15 \%$ of the total number of activities described. Their responses referred to 'reading texts extracted from newspapers and supplements (...)'. In 'Scientific communication', we included teachers' responses that referred to the activities devoted to reading scientific texts, understanding the scientific terminology, the vocabulary and so on. The fact that teachers had frequently mentioned the use of scientific texts and extracts from the newspapers - as activities intended to promote competences similar to those assessed by PISA - may be attributed to considering reading skills as a very important ability 
required to answer the PISA items or to considering it important to relate everyday news with school knowledge.

The category of 'Others' activities included $10 \%$ of the participants' responses that were not very specific (see Table 6) such as: 'We use activities that emphasize the relationships between all the experimental science subjects' or were addressed to a different kind of competences: 'exercises or role play to raise student' and 'awareness of environmental problems'.

\section{Conclusions and implications}

Considering the overall results from the questionnaire, we notice different perceptions of teachers when faced with the three scientific processes that are considered crucial for scientific literacy in PISA 2003.

Describing, explaining and predicting scientific phenomena (Process 1) was very commonly identified by teachers as the scientific process that is required by students for answering the items designed for such purposes. The relevance that teachers conceded to the competence of being able to apply scientific knowledge in different contexts or to describe or explain scientifically a situation was very high in most of the cases. Such relevance was as high when they were faced with the need to identify the demand in students' tests as when they had to predict the difficulties of their students when faced with the PISA tests. Moreover, the teachers in our sample said that they focused their class activities on promoting this competence in their students. It was the 'world' of scientific knowledge, on which teachers concentrated their efforts.

Less importance was attached to the mastery of scientific inquiry (Process 2), according to the responses of the teachers in our sample. On the average, only less than half of the participants $(5 / 30,11 / 30,15 / 30$ and 16/30; see Table 3$)$ noticed the demand of such competences in the 
items (1, 2, 3 and 8) designed to examine the abilities of students for analysing scientific research, for analysing the necessary actions to collect relevant data, or for testing some ideas. In addition, in the cases where teachers were aware of this scientific process (Process 2) being assessed, such recognition was so weak or the process was so far away from their minds that, when these teachers were asked for their students' possible difficulties for answering the items assessing his process only a minority (39\% or 25 of 65 of their responses) took Process 2 into consideration (see Table 5). Moreover, the sources of difficulties assigned to the items intended to assess the process of understanding scientific investigation, were not all about the learning of such process (a similar percentage $42 \%$ or 27 of 65 responses referred to other skills such as the possibility to use high cognitive skills or to read for understanding). Something parallel can be said for Process 3 that only 7 out of 39 responses or $18 \%$ of the participants that could identify this process being assessed could also find it a difficulty for their students. Thus, the consistency observed for Process 1 (73 out of 113 responses or 65\%) was not found for Processes 2 and 3 (see Table 5).

In any case, the scientific process least easily identified by the teachers was interpreting scientific evidence and drawing conclusions from data (Table 3). Furthermore, the need for students to be competent in such a process did not receive very much attention in the class activities mentioned (Table 6). This process seemed to be out of the teachers' minds and so, hardly (13 responses out of 240) any teachers mentioned it as a difficulty for students (Table $5)$.

On the other hand, we have to acknowledge the high sensitivity of our teachers to problems that students can have when faced with PISA tests in different directions not considered by the PISA tests. The categories of 'non-PISA processes' had scores higher than two PISA scientific processes (Processes 2 and 3) (see Table 5). Teachers were very sensitive to the demand of the PISA tests on the students due to the necessity to be fluent in reading for 
understanding and in being attentive and wakeful during the test time. We could also interpret that teachers weakly recognised that science education should include other competences different from mastering scientific facts or laws.

It has also to be remarked that such sensitivity seemed to be higher depending on the underlying scientific knowledge. When the topic worked out to be familiar to the teachers, they were more willing to take into consideration the diversity of processes. On the contrary, when faced with an unfamiliar context or a topic not usually taught, teachers were more inclined towards thinking within the requirements of scientific knowledge than looking at other processes (i.e., Processes 2 and 3) of the question.

Our study is limited by the kind of instruments to collect more data and by the small size of the sample. In fact, further studies and larger samples will be necessary to confirm and extend our conclusions. However, the need for enlarging the range of competences to be promoted in students seems to be evidenced by our results. The PISA tests are not only a challenge for 15year-old students but also for teachers themselves and for teacher educators as well.

In terms of teachers' training activities, the results of this study have various implications. First, general training activities can be suggested to help teachers learn more about 'scientific processes' required in science education and how such processes can be assessed. Second, more specific training activities can be proposed in order to help teachers identify the kind of situations that their students would be confronted with in real life as well as during their school education, and to promote a reflection about the most appropriate classroom activities to enhance different types of competences. Third, another implication of this study is the need for developing activities or identifying existing ones that would help teachers to put more emphasis on the different scientific processes in their classes.

\section{Acknowledgements}




\section{References}

Baker, R., Jones, A. (2005) How can international studies such as the international mathematics and science study and the programme for international student assessment be used to inform practice, policy and future research in science education in New Zealand? International Journal of Science Education, 27, 2, 145 - 157

Dossey, J. A., McCrone, S.A., and O'Sullivan, C. (2006, December). Problem Solving in the PISA and TIMSS 2003 Assessments (NCES 2007-049). U.S. Department of Education. Retrieved 18/04/2007, from http://nces.ed.gov/pubsearch

El Boudamoussi, S. Tortosa, M., and Pintó, R. (2008) La visión de los profesores de las competencias evaluadas en las pruebas PISA [The teachers' view of the competences evaluated in PISA tests].Alambique 57.

Ertl, H. (2006). Educational Standards and the Changing Discourse on Education: The Reception and Consequences of the PISA Study in Germany. Oxford Review of Education, 32(5), 619-634.

Fensham, P. J., Harlen, W. (1999) School science and public understanding of science. International Journal of Science Education, 21, 7, 755 - 763 
Ginsburg, A., Cooke, G., Leinwand, S. N., Jay, \& Pollock, E. (2005). Reassessing U.S. International Mathematics Performance: New Findings from the 2003 TIMSS and PISA: American Institutes for Research.

Goldstein, H. (2004). International Comparisons of Student Attainment: Some Issues Arising from the PISA Study. Assessment in Education Principles Policy and Practice, 11(3), 319-330.

Grisay, A., \& Monseur, C. (2007). Measuring the equivalence of item difficulty in the various versions of an international test. Studies in Educational Evaluation 33 (1), 69-86.

Hatzinikita , V, Dimopoulos, K., Christidou, V. (2008) PISA test items and school textbooks related to science: A textual comparison. Science Education, 92, 4, 664 - 687

Kjaernsli, M., \& Lie, S. (2004). PISA and Scientific Literacy: Similarities and Differences between the Nordic Countries. Scandinavian Journal of Educational Research, 48 (3), 271-286.

Lie, S., \& Linnakyla, P. (2004). Nordic PISA 2000 in a Sociocultural Perspective. Scandinavian Journal of Educational Research, 48(3), 227-230

Lietz, P. (2006). A Meta-Analysis of Gender Differences in Reading Achievement at the Secondary School Level Studies in Educational Evaluation, 32 (4), 317-344.

Livingston, K., \& McCall, J. (2005). Evaluation: Judgemental or Developmental? European Journal of Teacher Education, 28 (2), 165-178.

Marks, G. N. (2006). Are between- and within-School Differences in Student Performance Largely Due to Socio-Economic Background? Evidence from 30 Countries Educational Research, 48(1), 21-40.

Moens, F. (2006). PISA : Controverses et débats en Belgique francophone. Des indicateurs à la qualité ? [PISA: Controversies and debates in French-speaking Belgium. Quality indicators?]. Paper presented at the Colloque sur L'évaluation des politiques 
Neubrand, M. (2004). The PISA-Study: Differentiated assessment of "mathematical literacy". In J. Emanuelsson \& D. Clarke (Eds.), Contrasting comparative research on teaching and learning in mathematics. Cape Town: International Group for the Psychology of Mathematics Education.

OECD. (2002). Sample Tasks from the PISA 2000 Assessment: Reading, Mathematical and Scientific Literacy. Paris: OECD.

OECD. (2003). The PISA 2003 Assessment Framework: Mathematics, Reading, Science and Problem Solving Knowledge and Skills. Paris: OECD.

OECD. (2004). Learning for Tomorrow's World First Results from PISA 2003. Paris: OECD.

Simola, H. (2005). The Finnish Miracle of PISA: Historical and Sociological Remarks on Teaching and Teacher Education. Comparative Education, 41(4), 455-470.

Suchaut, B., Duru-Bellat, M., \& Mons, N. (2005). Organisation scolaire et inégalités sociales de performance : les enseignements de l'enquête PISA [School organisation and social inequalities of performance: the teachings of the PISA survey]. Education et formation, 70, 123-131.

Turmo, A. (2004). Scientific Literacy and Socio-Economic Background among 15-YearOlds--A Nordic Perspective. Scandinavian Journal of Educational Research, 48(3), 287-305.

van Langen, A., Bosker, R., \& Dekkers, H. (2006). Exploring Cross-National Differences in Gender Gaps in Education Educational Research and Evaluation, 12(2), 155-177

Willms, J. D. (2005). Why the Difference? Variation in Reading Scores among Canadian Provinces. Education Canada, 45(1), 54-55. 
Willms, J. D. (2006). Variation in Socioeconomic Gradients among Cantons in French and Italian-Speaking Switzerland: Findings from the OECD PISA. Educational Research and Evaluation, 12 (2), 129-154.

Wu, M. (2005). The Role of Plausible Values in Large-Scale Surveys. Studies in Educational Evaluation, 31(2), 114-128 
1

2

3

4

5

6

7

8

9

10

11

12

13

14

15

16

17

18

19

20

21

22

23

24

25

26

27

28

29

30

31

32

33

34

35

36

37

38

39

40

41

42

43

44

45

46

47

48

49

50

51

52

53

54

55

56

57

58

59

60

\section{Table Captions}

Table 1. Descriptors of the scientific processes assessed by PISA

Table 2. Characteristics of the selected PISA items included in the study

Table 3. Number of participants who identified the competence for which the item has been designed $(n=30)$

Table 4. Number of participants by category of expected difficulties $(n=30)$

Table 5. Number of responses of participants that considered as "a difficulty" a competence they identified as being assessed by a test item.

Table 6. The scientific processes promoted by teachers in their classes 
Table 1. Descriptors of the scientific processes assessed by PISA

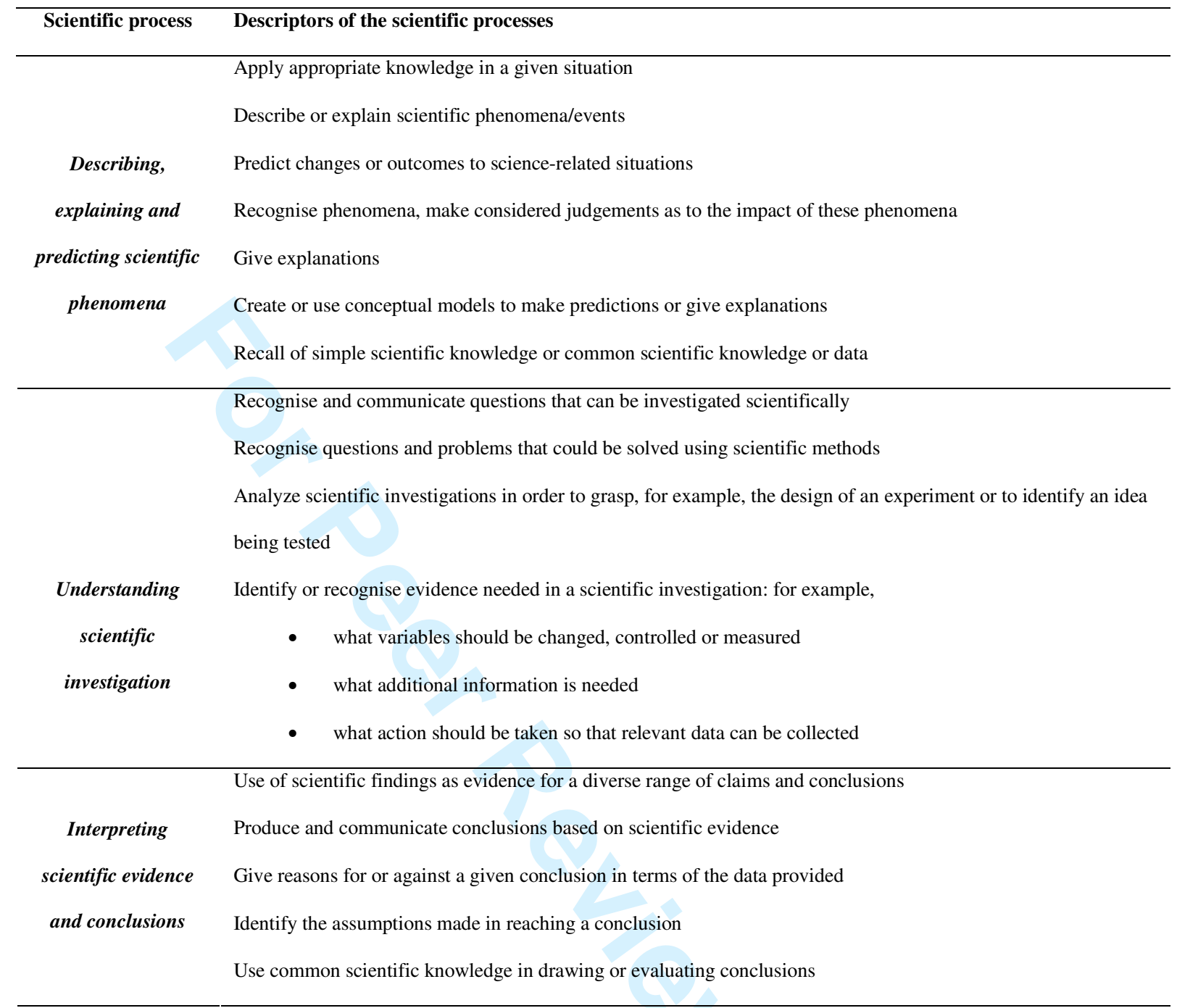


Table 2. Characteristics of the selected PISA items included in the study

\begin{tabular}{|c|c|c|c|}
\hline Item & $\begin{array}{l}\text { Unit (and number } \\
\text { of item in PISA } \\
\text { test) }\end{array}$ & Scientific process & Aspects of the scientific process focused on the item \\
\hline 1 & $\begin{array}{l}\text { ¡Stop that Germ! } \\
\left(1{ }^{\text {st }} \text { item }\right) \\
\text { ¿Stop that Germ! } \\
\left(2^{\text {nd }} \text { item }\right)\end{array}$ & $\begin{array}{l}\text { Understanding scientific } \\
\text { investigation }\end{array}$ & $\begin{array}{l}\text { - Analyze scientific investigations in order to grasp, for example, } \\
\text { the design of an experiment or to identify an idea being tested } \\
\text { - Identify and recognise evidence needed in a scientific } \\
\text { investigation, particularly the additional information needed }\end{array}$ \\
\hline 3 & $\begin{array}{c}\text { Peter Cairney } \\
\left(1^{\text {st }} \text { item }\right)\end{array}$ & $\begin{array}{l}\text { Understanding scientific } \\
\text { investigation }\end{array}$ & $\begin{array}{l}\text { - Identify and recognise evidence needed in a scientific } \\
\text { investigation, particularly, the action to carry out to collect } \\
\text { relevant data }\end{array}$ \\
\hline 4 & $\begin{array}{l}\text { Peter Cairney } \\
\qquad\left(2^{\text {nd }} \text { item }\right)\end{array}$ & $\begin{array}{l}\text { Interpreting scientific evidence } \\
\text { and conclusions }\end{array}$ & $\begin{array}{l}\text { - Give reasons for or against a given conclusion in terms of the } \\
\text { data provided. }\end{array}$ \\
\hline 5 & $\begin{array}{l}\text { Peter Cairney } \\
\qquad\left(3^{\text {rd }} \text { item }\right)\end{array}$ & $\begin{array}{l}\text { Describing, explaining and } \\
\text { predicting scientific phenomena }\end{array}$ & $\begin{array}{l}\text { - Give an explanation } \\
\text { - Apply appropriate knowledge in a given situation } \\
\text { - Describe or explain a scientific phenomenon }\end{array}$ \\
\hline 6 & Corn $\left(3^{\text {rd }}\right.$ item $)$ & $\begin{array}{l}\text { Interpreting scientific evidence } \\
\text { and conclusions }\end{array}$ & - Identify the assumptions made in reaching a conclusion. \\
\hline 7 & $\begin{array}{l}\text { Ozone } \\
\left(1^{\text {st }} \text { item }\right)\end{array}$ & $\begin{array}{l}\text { Describing, explaining and } \\
\text { predicting scientific phenomena }\end{array}$ & $\begin{array}{l}\text { - Give an explanation } \\
\text { - Apply appropriate knowledge in a given situation } \\
\text { - Describe or explain a scientific phenomenon } \\
\text { - Recognise phenomena, make considered judgements as to the } \\
\text { impact of these phenomena } \\
\text { - Create or use conceptual models to make predictions or give } \\
\text { explanations }\end{array}$ \\
\hline 8 & $\begin{array}{c}\text { Ozone } \\
\left(4^{\text {th }} \text { item }\right)\end{array}$ & $\begin{array}{l}\text { Understanding scientific } \\
\text { investigation }\end{array}$ & - Recognise or identify scientifically investigable questions \\
\hline
\end{tabular}


Table 3. Number (percentage) of participants who identified the competence for which an item has been designed $(n=30)$

\begin{tabular}{|c|c|c|c|c|c|c|c|c|}
\hline Item & \multicolumn{2}{|c|}{$\begin{array}{l}\text { Describing, } \\
\text { explaining and } \\
\text { predicting } \\
\text { scientific } \\
\text { phenomena }\end{array}$} & \multicolumn{2}{|c|}{$\begin{array}{l}\text { Understanding } \\
\text { scientific } \\
\text { investigation }\end{array}$} & \multicolumn{2}{|c|}{$\begin{array}{c}\text { Interpreting } \\
\text { scientific evidence } \\
\text { and conclusions }\end{array}$} & \multirow[t]{2}{*}{$\begin{array}{c}\text { Reading } \\
\text { comprehension }\end{array}$} & \multirow{2}{*}{$\begin{array}{l}\text { Using cognitive } \\
\text { skills } \\
\\
\\
0\end{array}$} \\
\hline Item 1 & 19 & $(63.3)$ & 5 & $(16.7)$ & 6 & (20.0) & & \\
\hline Item 2 & 7 & (23.3) & 11 & (36.7) & 3 & (10.0) & 4 & 5 \\
\hline Item 3 & 7 & (23.3) & 15 & $(50.0)$ & 7 & (23.3) & 0 & 1 \\
\hline Item 4 & 4 & (13.3) & 3 & $(10.0)$ & 17 & (56.7) & 5 & 1 \\
\hline Item 5 & 27 & $(90.0)$ & 1 & $(3.3)$ & 0 & $(0.0)$ & 1 & 1 \\
\hline Item 6 & 13 & (43.3) & 12 & $(40.0)$ & 4 & (13.3) & 1 & 0 \\
\hline Item 7 & 27 & $(90.0)$ & 2 & (6.7) & 0 & $(0.0)$ & - & - \\
\hline Item 8 & 9 & $(30.0)$ & 16 & (53.3) & 2 & $(6.7)$ & 1 & 2 \\
\hline Total & 113 & (47.1) & 65 & $(27.1)$ & 39 & (16.3) & 12 & 10 \\
\hline
\end{tabular}

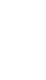

6

(1)


Table 4. Number (percentage) of participants by type of expected difficulties $(n=30)$

\begin{tabular}{|c|c|c|c|c|c|}
\hline Item & $\begin{array}{l}\text { Describing, } \\
\text { explaining and } \\
\text { predicting scientific } \\
\text { phenomena }\end{array}$ & $\begin{array}{l}\text { Understanding } \\
\text { scientific } \\
\text { investigation }\end{array}$ & $\begin{array}{l}\text { Interpreting } \\
\text { scientific evidence } \\
\text { and conclusions }\end{array}$ & $\begin{array}{l}\text { Reading } \\
\text { comprehension }\end{array}$ & $\begin{array}{c}\text { Using cognitive } \\
\text { skills }\end{array}$ \\
\hline Item 1 & \begin{tabular}{|ll}
22 & $(73.3)$
\end{tabular} & $0(0.0)$ & $0(0.0)$ & 5 (16.7) & $3(10.0)$ \\
\hline Item 2 & $11(36.7)$ & 8 (26.7) & $1(3.3)$ & $8(26.7)$ & $2(6.7)$ \\
\hline Item 3 & $2 \quad(6.7)$ & $11(36.7)$ & $1(3.3)$ & $9(30.0)$ & $7(23.3)$ \\
\hline Item 4 & $5 \quad(16.7)$ & $6(20.0)$ & $8(26.7)$ & $5(16.7)$ & $6(20.0)$ \\
\hline Item 5 & $22(73.3)$ & $1(3.3)$ & $0(0.0)$ & $4(13.3)$ & $3(10.0)$ \\
\hline Item 6 & $17(56.7)$ & $2(6.7)$ & $0(0.0)$ & $9(30.0)$ & $2(6.7)$ \\
\hline Item 7 & $20(66.7)$ & $0(0.0)$ & $0(0.0)$ & $9(30.0)$ & $1(3.3)$ \\
\hline Item 8 & $4(13.3)$ & $13(43.3)$ & $3(10.0)$ & $8(26.7)$ & $2(6.7)$ \\
\hline Total & 103(42.9) & 41(17.1) & $13(5.4)$ & $57(23.8)$ & $26(10,8)$ \\
\hline
\end{tabular}


Table 5. Number of responses of participants $(n=30)$ that considered as "a difficulty" a competence they had identified as being assessed by a test item

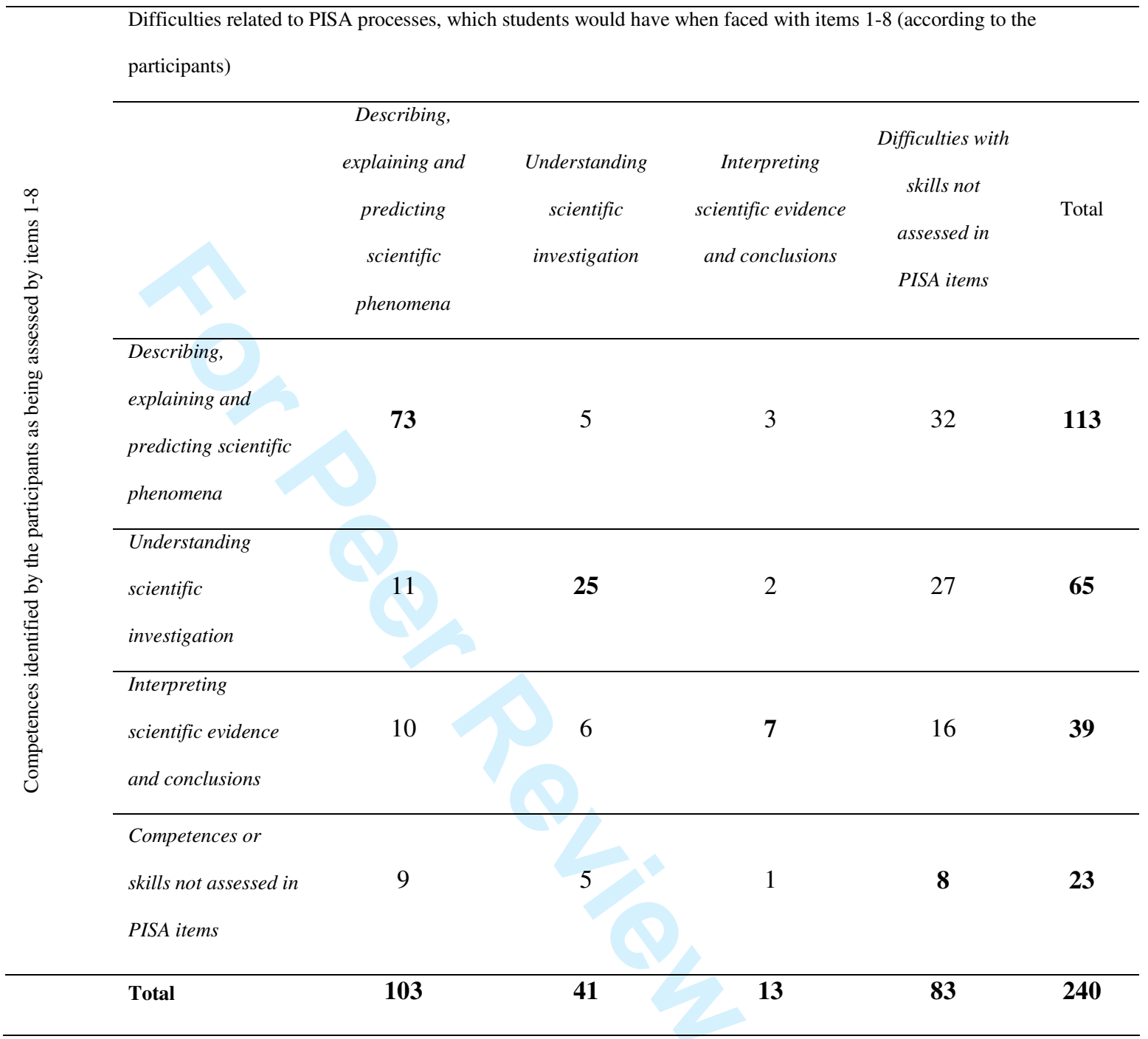


Table 6. The scientific processes promoted by teachers in their classes

\begin{tabular}{lcc}
\hline Scientific process assessed by PISA items & Activities described by teachers \\
\hline Describing, explaining and predicting scientific phenomena & 39 & $37 \%$ \\
Understanding scientific investigation & 26 & $25 \%$ \\
Interpreting scientific evidence and conclusions & 14 & $16 \%$ \\
Scientific communication & 11 & $15 \%$ \\
Others or vague answers & $10 \%$ \\
\hline
\end{tabular}


Appendix 1: The Questionnaire

1) Which are the competences that you consider being assessed by each of the items of this hypothetical test?

2) Which are the difficulties that you think your students may have to respond to an evaluation test of this type?

3) Name briefly examples of activities that you use in your classes to promote some of the competences you had previously identified in the hypothetical test.

\begin{tabular}{l}
\hline An example of the chosen PISA items for the study \\
Other items used in the research study can be found in: \\
http://antalya.uab.es/crecim/PISA_study 1 and 2 of the questionnaire
\end{tabular}
STOP THAT GERM! ${ }^{1}$ Competences assessed by Item 1:

As early as the 11th century, Chinese doctors were manipulating the immune system. By blowing pulverised scabs from a smallpox victim into their patients' nostrils, they could often induce a mild case of the disease that prevented a more severe onslaught later on. In the 1700 s, people rubbed their skins with dried scabs to protect themselves from the disease. These primitive practices were introduced into England and the American colonies. In 1771 and 1772, during a smallpox epidemic, a Boston doctor named Zabdiel Boylston tested an idea that he had. He scratched the skin on his sixyear-old son and 285 other people and rubbed pus from smallpox scabs into the Competences assessed by Item 2 : wounds. All but six of his patients survived.

\section{ITEM 1:}

What idea might Zabdiel Boylston have been testing?

ITEM 2:

Give two other pieces of information that you would need to decide how successful Boylston's approach was.

1 Science Unit 1: Stop that Germ! The PISA 2003 Assessment Framework: Mathematics, Reading, Science and Problem Solving Knowledge and Skills, (C) OECD 2004 